\title{
Correction to: Cupriavidus malaysiensis sp. nov., a novel poly(3-hydroxybutyrate-co-4-hydroxybutyrate) accumulating bacterium isolated from the Malaysian environment
}

\author{
Hema Ramachandran • Nur Asilla Hani Shafie - Kumar Sudesh • \\ Mohamad Noor Azizan - Mohamad Isa Abdul Majid - Al-Ashraf Abdullah Amirul
}

Published online: 28 December 2017

(C) Springer International Publishing AG, part of Springer Nature 2017

\section{Correction to: Antonie van Leeuwenhoek https://doi.org/10.1007/s10482-017-0958-8}

In the original publication of the article, it was noted that Fig. 1 present an image of Cupriavidus malaysiensis strain USMAHM13 and not of strain USMAA1020, as indicated in the figure legend. The image in the original version is thus noted to serve as a record of strain USMAHM13 and the corrected version of Fig. 1 is reprinted below.

The original article can be found online at https:// doi.org/10.1007/s10482-017-0958-8.

H. Ramachandran · K. Sudesh · A.-A. A. Amirul ( $\square)$ School of Biological Sciences, Universiti Sains Malaysia, 11800 Penang, Malaysia

e-mail: amirul@usm.my

H. Ramachandran

Quest International University Perak, 30250 Ipoh, Perak, Malaysia

N. A. H. Shafie - A.-A. A. Amirul

Centre for Chemical Biology, Universiti Sains Malaysia,

Sains@USM, 11900 Bayan Lepas, Penang, Malaysia

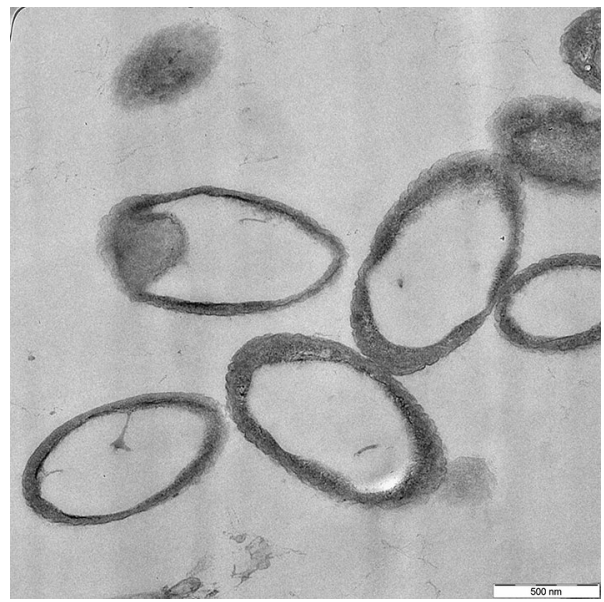

Fig. 1 Transmission electron micrograph of Cupriavidus malaysiensis USMAA1020 $0^{\mathrm{T}}$ grown in MSM containing $\gamma$ butyrolactone for $48 \mathrm{~h}$ through one-stage cultivation. Bar represents $500 \mathrm{~nm}$

M. N. Azizan

Universiti Kuala Lumpur (UniKL-MICET) Taboh

Naning, 78000 Alor Gajah, Melaka, Malaysia

M. I. A. Majid

National Poison Centre, Universiti Sains Malaysia, 11800 Penang, Malaysia

A.-A. A. Amirul

Malaysian Institute of Pharmaceuticals and Nutraceuticals (IPharm), National Institutes of Biotechnology Malaysia (NIBM), MOSTI, 11700 Penang, Malaysia 